\title{
Appropriation of an Activity-based Flexible Office in daily work'
}

I Maral Babapour ${ }^{2}$

Division Design \& Human Factors, Department of Industrial and Materials Science, Chalmers University of Technology, Sweden.

I MariAnne Karlsson

Division Design \& Human Factors, Department of Industrial and Materials Science, Chalmers University of Technology, Sweden.

\section{Anna-Lisa Osvalder}

Division Design \& Human Factors, Department of Industrial and Materials Science, Chalmers University of Technology, Sweden.

\begin{abstract}
In recent years, there has been growing interest in collaborative consumption of office environments and thereby implementation of Activity-based Flexible Offices (A-FOs). Relocating to an A-FO introduces a desk-sharing policy as well as a multitude of new workspaces with different speech policies into the employee's work context. This paper describes how employees appropriate desk-sharing and speech policies in an A-FO. The data were collected over a period of 6 months in a case organization by means of 18 shadowing sessions. The different ways in which employees appropriated the A-FO solution were (i) adopting, experimenting with, or rejecting the desk-sharing policy, and (ii) modes of interaction arising from spatial configuration and redefining speech policies. The discussion outlines the reasons behind appropriation or nonappropriation of the desk-sharing and emergent speech policies. The insights from this study provide support for organizations considering A-FOs to develop strategies for facilitating individuals' work in these settings.
\end{abstract}

\section{KEYWORDS}

Activity-based workplace (ABW) / adoption of innovation / appropriation / coworking space / field study / new ways of working / office layout / work environment / workspace design

\section{Introduction}

he widespread deployment of Information and Communication Technologies in recent
years has provided opportunities for work to extend beyond a single office, allowing it
to take place across multiple locations. This is one of the several ways in which flexi-
bility has increased in the labor market in Sweden (Allvin et al., 2013). Changes have been
introduced in the otherwise regulatory conditions of work, specifically in terms of time
and place for work, as well as performance and requirements of project work and col-
laboration in a professional network (ibid.). These changes have given rise to new ways of
exploiting workspaces, namely coworking spaces that involve collaborative consumption

\footnotetext{
${ }^{1}$ You can find this text and its DOI at https://tidsskrift.dk/njwls/index.

2E-mail: maral@chalmers.se
} 
of office environments, shared between individuals with different backgrounds or from different organizations who engage in collaborative knowledge work (Parrino, 2015; Spinuzzi, 2012). Coworking spaces range from public workspaces open for independent individuals, to private ones dedicated to a certain interest group or organizations' own employees (Kojo \& Nenonen, 2016). Coworking spaces are mostly configured as flexible offices offering a variety of workspaces without assigned workstations (ibid.).

From a historical perspective, developments in office configurations have been coupled with advancements in building technology and developments such as air conditioning and fluorescent lighting (Sundstrom \& Sundstrom, 1986). Open plan offices (OPOs) have been the most common office types in the US from the early 1900s (ibid.). These offices were configured with standardized workplaces to improve work processes and facilitate having an overview of ongoing work (Sundstrom \& Sundstrom, 1986; van Meel, 2000). To improve work conditions such as lack of privacy in OPOs, innovations in configuration of workspaces were initiated in Europe and the US in the 60s and 70s (Sundstrom \& Sundstrom, 1986). This involved use of panels to create enclosed group areas and introduction of moveable interlocking partitions, that is, cubicles to allow for privacy and concentration (ibid.). With the increased influence of employees in organizational decision-making in Europe in the 70s, some countries adopted regulations for use of space per employee, access to daylight and outside views (van Meel, 2000). As a result, cellular offices became the predominant office solution (ibid.). In recent decades, there has been a growing interest in replacing cell-offices with OPOs and Activity-based Flexible Offices (A-FOs), to reduce costs associated with cell-offices and facilitate collaboration among coworkers (Myerson \& Ross, 2003; Ross et al., 2017). In Sweden, among the employed workforce spending a minimum of one-fourth of their work hours in an office in $2015,18 \%$ worked in OPOs with 10 or more persons, and $14 \%$ worked in A-FOs (Swedish Work Environment Authority, 2016).

A-FOs are also called hot-desking offices, non-territorial offices, and Activity-Based Workplaces or ABWs (Brunia et al., 2016; Kim et al., 2016; Knight \& Haslam, 2010). They are typically dimensioned for $70 \%$ of the workforce depending on the expected presence of employees (Bodin Danielsson \& Bodin, 2008). Therefore, a desk-sharing or hot-desking policy is devised in A-FOs to facilitate the rotation of individuals and teams and free up workspaces (ibid.). In an office that follows a desk-sharing policy, workstations are taken on a first-come-first-served basis and the employees are required to leave the workstations clean and undecorated after daily use (Knight \& Haslam, 2010). In addition, A-FOs provide a variety of spaces for solitary and collaborative work to allow people to choose a 'workstation that best suits the activity at hand' (Appel-Meulenbroek et al., 2011). Organizational goals behind implementing A-FOs may range from optimizing the use of space and resources to improving the work environment and organizational image, increasing productivity, knowledge sharing, and collaborations (De Been $\&$ Beijer, 2014; van der Voordt, 2004). Increased employee mobility is a key factor that facilitates the achievement of these goals.

Studies on work environment consequences of relocating to A-FOs seem to have partly conflicting results. While some studies report on increased work satisfaction due to the ability to choose a workstation according to personal preferences and task-related needs (e.g., Bodin Danielsson \& Bodin, 2008), others report dissatisfaction due to having unassigned workstations, misuses, and productivity loss (e.g., Appel-Meulenbroek et al., 2011). Other aspects associated with a loss of productivity are traveling within the 
office, finding workspaces, setting-up, and packing away belongings (Kim et al., 2016). Research results are also inconsistent regarding whether A-FOs lead to increased distractions (De Been \& Beijer, 2014; Seddigh et al. 2014). Furthermore, while some studies report that A-FO solutions lead to increased communication (e.g., Boutellier et al., 2008; van der Voordt, 2004; Vos \& van der Voordt, 2002), others report decreased communication (De Been \& Beijer, 2014; Kim et al., 2016).

In the Nordic context, work environment is regarded as 'every aspect of work and its conditions that may affect workers' health' (Frick, 2013). Findings from studies on A-FOs have implications for a multitude of aspects regarding work life from organizational culture, structure, and processes (Skogland, 2017), to employees' health and wellbeing (Meijer et al., 2009). However, some researchers report that A-FOs are not used as intended, for instance quiet zones are not used for concentrative work (AppelMeulenbroek et al., 2011) or employees tend to claim and use the same workstations in A-FOs (Hirst, 2011). A-FOs' implications for work life remain unclear specifically regarding whether they are due to intended or unintended ways in which employees use A-FOs. Having said that, research is sparse regarding employees' processes of adopting flexible ways of working in A-FOs (Sim \& Heywood, 2017).

Regarding A-FOs as innovations in the work context, the purpose of this study is to better understand employees' processes of appropriating A-FOs after relocation.

\section{Appropriation and adoption of innovation}

Innovation is defined as an idea or practice, or an object 'that is perceived new by an individual or other unit of adoption' (Rogers, 1995). The perceived newness for the individual determines whether the concept is an innovation or not (ibid.). In this paper, A-FOs are regarded as innovations in the work context for employees and organizations due to (i) introduction of new work practices such as desk-sharing and new configuration of workspaces, and (ii) perceived newness when relocating from other office types, although the organization may not be the first one to implement A-FOs. After relocating to an A-FO, new work practices and a multitude of new workstations and zones are to be chosen, appropriated, and used together with other artefacts (such as laptops and mobile phones) that the users or the organization bring from their former premises. According to Bødker and Klokmose (2011), the choices users make between different artefacts (i.e., A-FO's different workstations and zones) depend on their activities and the intended outcomes. Carroll et al. (2002) define appropriation as the way in which 'artefacts are adopted, shaped and then used', starting when the users decide to experiment with an innovation. This can either lead to integration of the new concept into the users' everyday lives or dis-appropriation and rejection of the innovation. They also introduce the concept of nonappropriation, that is, when the users choose not to experiment with or evaluate the innovation (ibid.). One closely related concept is Rogers' innovation-decision process (1995) during which individuals evaluate a new idea or technology and choose either to reject or integrate it into their everyday lives.

Users go through different phases when appropriating and adopting an innovation: first encounters, exploration, and stable phases. In the first phase, the user identifies a need for change, gains knowledge about an innovation, and decides to acquire it (cf. first knowledge, forming an attitude, and decision in Rogers, 1995; unsatisfactory state in 
Bødker \& Klokmose, 2012). This is a mental process that involves dealing with uncertainties and deciding about a new alternative to replace the existing ones (Rogers, 1995). In the exploratory phase, users experiment with the innovation to explore its potential (cf. implementation in Rogers, 1995; excited state in Bødker \& Klokmose, 2012). This involves a mix of old and newly developed routines and various setup problems that introduce tensions into the users' activities (Bødker \& Klokmose, 2012). Individuals seek to avoid or reduce this tension during the implementation process (Rogers, 1995). The stable phase involves long-term integration of the innovation into the users' everyday activities (cf. confirmation in Rogers, 1995; stable state in Bødker \& Klokmose, 2012). In this phase, the individual seeks reinforcement or reverses a previous decision and dis-appropriates the innovation due to identification of new needs (cf. Bødker \& Klokmose, 2012; Carroll et al., 2002; Rogers, 1995).

Reaching intended outcomes of an innovation relies on users' acceptance of the concept (Davis, 1989). The adoption of innovation and its rate, according to Rogers (1995), depends on its perceived attributes among the users: (i) relative advantage for the users, (ii) compatibility with existing knowledge system and ways of doing things, (iii) complexity, that is, the degree to which it is difficult to understand and use, (iv) observability, that is, the extent to which its results are visible, and (v) trialability, that is, the extent to which it may be experimented with.

The notion of appropriation and adoption of innovation is used in this paper to (i) explore how employees incorporate new work practices and workspaces into their daily work after relocating to an A-FO, and (ii) identify and discuss the attributes of the A-FO solution that had an impact on the rate of adoption. More specifically, the aim is to better understand the processes that lie behind adopting and adapting one's ways of working when relocating to an A-FO.

\section{Research approach}

A case study approach was chosen to enable the understanding of individuals' processes of adopting and adapting to an A-FO by observing activities and interactions of employees in an organization. A case study is an in-depth description and analysis of an instance of 'some phenomenon, a programme, a group, an institution or a community' (Merriam, 2009). It is designed to collect detailed information of one or several cases, by using multiple sources of data (Creswell, 2013).

\section{The case organization}

The case organization was a Science Park with 12 full-time employees and one part-time employee. Its main service involved creating collaboration platforms to bring together stakeholders from industry, academia, and city government to address societal challenges such as sustainable urban development. The relocation was a part of a larger development of facilities and amenities in the area. The A-FO was designed to accommodate 60-80 employees from different organizations (Fig. 1). This was regarded beneficial both from employees' and management's perspective for the ability of the organization to provide collaboration opportunities for different stakeholders. The employees had no 
Figure I: The A-FO layout, distribution of the different workspaces, and examples of solitary and collaborative workstations. The A-FO was located on the second floor of two buildings that were connected by a bridge.

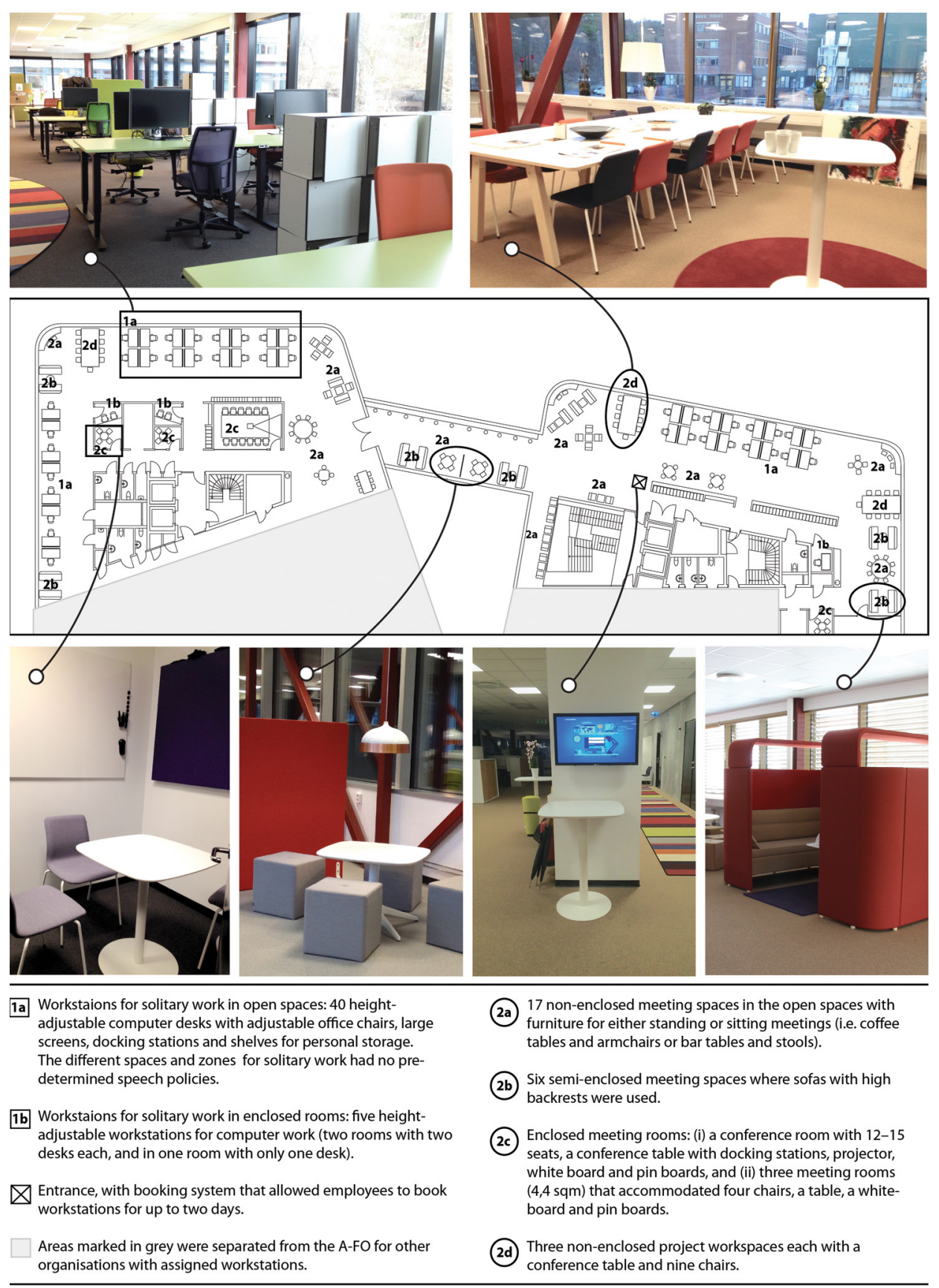


involvement in the design and planning process. Choices regarding office type, layout and configuration, and the business model behind the coworking spaces were made by the facility owner that was one of the financiers of the case organization. These choices were communicated with the employees six months prior to the relocation.

The relocation involved (i) moving from a cell-office after 15 years to an A-FO, (ii) sharing the new premises with some of the organization's owners and partners, and (iii) providing coworking spaces as a part of their services. The case organization was selected for this study since the employees were among the first tenants to use the premises full-time. This is while the remaining tenants had either allocated workstations or permanent workstations at their organizations elsewhere and would use the workspaces mostly for collaborative work.

\section{Participants}

Being introduced to an A-FO without prior experience of working in flexible offices was the main criteria for considering this relocation as an innovation. The 12 full-time employees of the case organization (five men and seven women aged 27-65 years) had no prior experience of working in A-FOs apart from P-12 who was employed after relocation. The participants' main responsibility was to contribute to creating collaboration platforms in different ways (see the participants' responsibilities in Table 1). Their activities involved engaging different stakeholders from academia, industry, and city government for (i) writing applications to obtain resources for project collaborations, (ii) coordinating development projects, (iii) authoring project reports, and (iv) disseminating knowledge through seminars and other communication channels. The themes of these projects varied from urban development to energy and materials technology. In addition, they provided a network of Small and Medium-Sized Enterprises with support services such as marketing, business development, and access to events and seminars for knowledge sharing and competence development.

Table I An overview of the participants' responsibilities within the case organization

\begin{tabular}{ll}
\hline \multicolumn{2}{l}{ Participants' responsibilities } \\
\hline P-I & Tracks, anchors, and coordinates development projects; Staff management. \\
\hline P-2 & Tracks, anchors, and coordinates development projects. \\
\hline P-3 & Tracks, anchors, and coordinates development projects. \\
\hline P-4 & Creates collaborative contexts for SMEs. \\
\hline P-5 & Works with business development for external organizations. \\
\hline P-6 & Responsible for the case organization's marketing and business development. \\
\hline P-7 & Coordinates a number of shared development projects. \\
\hline P-8 & Responsible for communication planning. \\
\hline P-9 & Responsible for authoring newsletters with different themes. \\
\hline P-10 & Tracks, anchors, and coordinates international projects. \\
\hline P-11 & Tracks, anchors, and coordinates development projects. \\
\hline P-12 & Responsible for communication planning and contacts with industry. \\
\hline
\end{tabular}




\section{Shadowing sessions: the fieldwork}

A shadowing study of the 12 full-time employees of the case organization started four weeks after relocating to the A-FO. The study focused on activities and interactions of the participants that took place within their office premises. Shadowing is a direct, nonparticipant observation technique where the observer 'follows selected people in their everyday occupations for a time' (Czarniawska, 2007). Shadowing was chosen since its main advantage is the possibility of capturing the mobility of 'contemporary life' (ibid.). Observing work in A-FOs requires moving between different locations when participants switch workstations. Since the employees' former offices were in proximity to the new one, the relocation took place gradually, that is, some of the participants occasionally used the old offices in the first few weeks. Therefore, the shadowing started four weeks after relocation, when all of the participants started working exclusively in the new premises and had no access to their former premises.

In total, 18 weekly shadowing sessions were held (Fig. 2). Each session lasted four hours. The sessions were spread across different work hours and weekdays, since use of workspaces was anticipated to change during the day or week. The shadowing sessions comprised taking structured field notes and engaging in unstructured interviews (when possible). Each session started by locating the participants, greeting them, and finding an appropriate place in their proximity for observing. The priority was to find a location for observations where it was possible to see the majority of the participants. This involved following them when they changed workstations within the premises except for some of the meetings that were held in the enclosed rooms. Effort was made not to distract and interrupt the participants when they were working. Unstructured interviews were conducted when the participants were about to leave or upon their arrival, or when they initiated conversations.

Figure 2: Observation sessions throughout the fieldwork ( $\mathrm{S}=$ session).

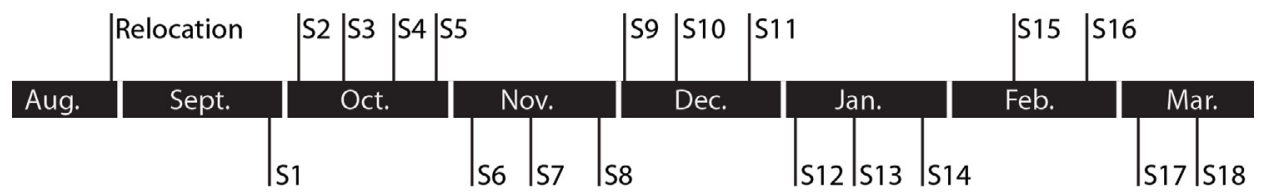

The fieldnotes involved blueprint annotations and logging of the participants' activities and interactions: (i) the nature of activities, that is, solitary work, inter- and intra-team activities, and informal interactions, (ii) the number of people involved, (iii) whether the interaction was planned or spontaneous, (iv) whether it was via phone or Skype, (v) the workstation used during the interaction, and (vi) time of the activity. The unstructured interviews and informal conversations with and between the participants that addressed issues regarding A-FOs were also documented as free-form text.

\section{Analysis}

The analysis involved a bottom-up approach and started with open-coding to identify, name, and categorize the data by reading through the field notes and creating themes 
(cf. Miles \& Huberman, 1994). After categorization of the activities and events (Table 2), their occurrence across the 18 occasions was compared. The documented conversations with and between the participants were included in the analysis and used as quotes to communicate the findings. These quotes are marked with Participant and Session number (e.g., P1-S1). In addition, the blueprint annotations were used to illustrate examples of workspace choices over time.

Table 2 Categorization of data

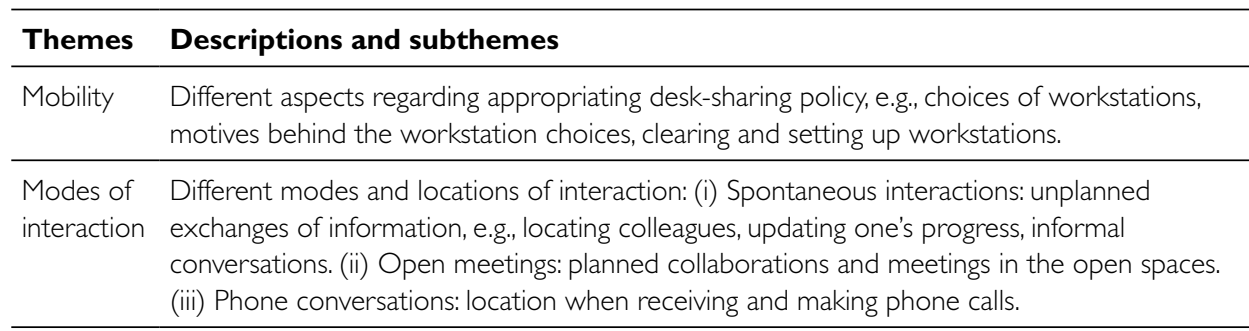

\section{Results}

The analysis resulted in two main themes addressing (i) individuals' processes of adopting and adapting desk-sharing policy and their preferences regarding switching workstations, and (ii) new modes of interaction arising from the spatial configuration and emergent speech policies.

\section{Appropriation of desk-sharing policy}

After an introductory phase of getting familiarized with the new premises, a group of participants adopted the desk-sharing policy and switched between different workstations (mobile workers, $\mathrm{n}=3$ ), while others rejected the policy and used one workstation throughout the fieldwork (dwellers, $n=6$ ). A third group of participants experimented with flexible ways of working and moved between adopting and rejecting the desksharing policy during the fieldwork (experimenters, $n=3$ ).

\section{Mobile workers: Adoption of desk-sharing policy}

Mobile workers followed the desk-sharing policy and used different workstations for solitary and collaborative activities throughout the fieldwork (e.g., Fig. 3). They removed their belongings from the workstations when they were elsewhere. The mobile workers used their laptops without a mouse, a keyboard, or the large screens available at the workstations. This minimized set-up time when switching workstations and provided them with spatial mobility within and outside the premises' boundaries: 'I am taking my office to the car for the rest of the day' (P12-S16). However, set-up problems were not eliminated especially when the mobile workers needed larger screens for their work (due to the incompatibility of device drivers and screens): 'it takes 35 minutes to restart the computer every time you switch the workstation' (P8-S8). 
During the first month after relocation, the mobile workers had identified workstations that they preferred: 'it is nice to see who comes in here [close to the entrance], but in the second row, you have better lighting and it is not as cold' (P12-S1). The mobile workers also appreciated access to their colleagues and quick information exchanges. The mobile workers encouraged their colleagues to follow the desk-sharing policy and reminded them to 'clear out the workstations' (P8-S7). They showed concerns about whether they could use all of the workstations: 'can I book these workstations and tell dwellers "sorry! Today I am going to sit here, please collect your folders and move"' (P9S4). In the stable phase, the mobile workers repeatedly returned to a few workstations that they preferred (sessions 5, 6, 7, 9, 10 in Fig. 3).

Figure 3: A mobile worker's choices of workstations during the fieldwork (the numbers represent the different shadowing sessions).

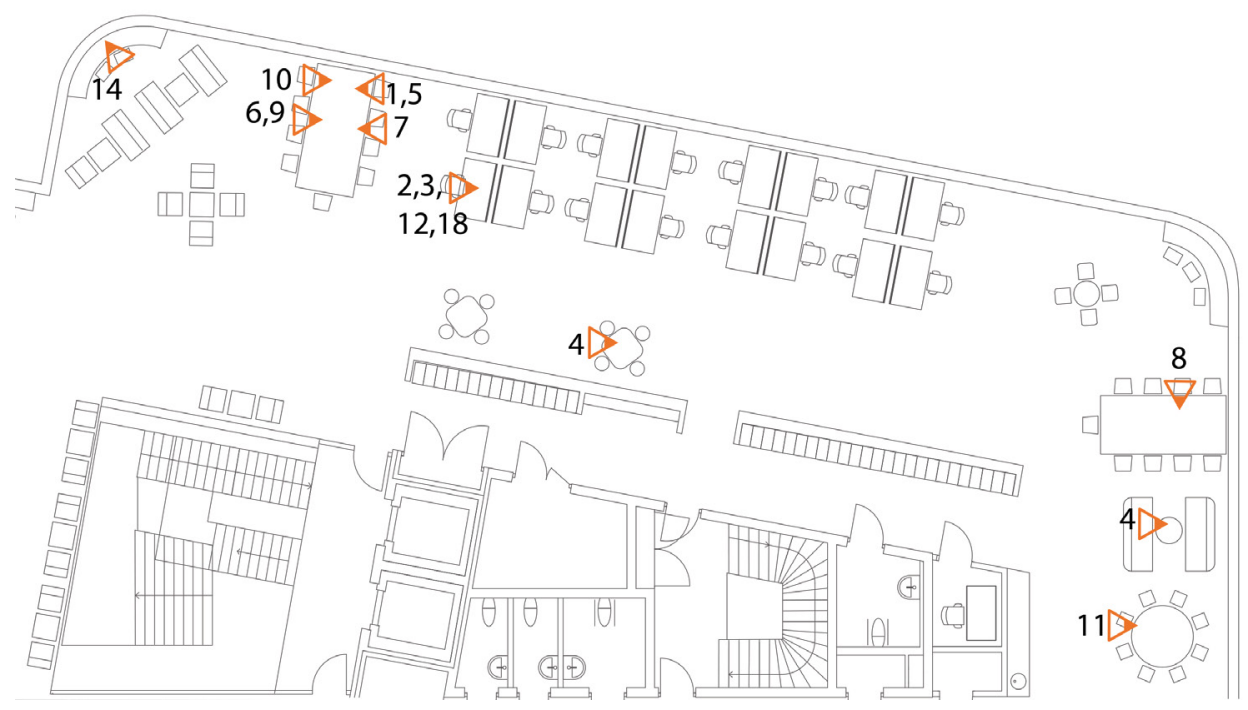

\section{Dwellers: Rejection of desk-sharing policy}

Some of the participants used the same workstations throughout the fieldwork, mentioning that 'I have chosen a real place' (P6-S1) or 'I sit at the same place and refuse to change' (P10-S8). The dwellers left their belongings on the desks when leaving work (Fig. 4). Some of the more common artefacts left at the workstations were folders, office supplies, and business cards. In addition, one of the dwellers brought a 'more ergonomic chair' that he found easily adjustable, and a desk lamp for improved lighting: 'I am old and need extra lighting' (P6-S4).

The A-FO solution was unsatisfactory for the dwellers, since it introduced obstacles for their activities. Following the desk-sharing policy would require additional time and effort for transporting and setting up a workstation. The desk-sharing policy was also considered incompatible with the dwellers' work that required using and spreading printed documents, for instance when writing reports. In addition, the desks were regarded as too small for spreading out and gaining an overview of ongoing work. Using 
Figure 4: Examples of dwellers' workstations marked with their belongings neighboring workstations that were cleared out.
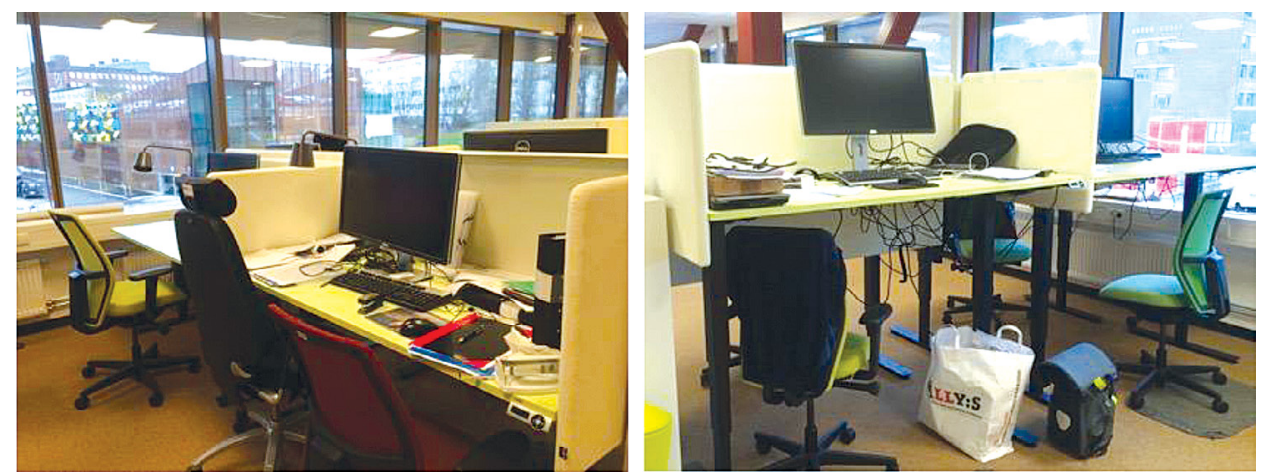

the same workstations helped dwellers to cope with these obstacles. Furthermore, insufficient technical support (such as incompatibility of screens, docking stations, and device drivers) led to set-up problems and hindered spatial mobility. Another reason for using the same workstations was proximity to colleagues: 'I prefer to sit next to my colleagues, not people I am not collaborating with' (P4-S1). In session 12, one of the dwellers raised his concerns with the staff manager: 'I need a larger desk for my things. In fact, I need my own desk. I can't properly do my work tasks' (P6-S12). As a result, a separate office outside the premises was allocated for him. Limited options were offered to tailor the workspaces. Since different organizations were using the premises, the facility management strove to keep the facilities as generic as possible.

\section{Experimenters:Shifting betweenadoptionand rejection of desk-sharingpolicy}

Shifting between adopting and rejecting the desk-sharing policy among experimenters involved finding a workstation that they preferred and used for approximately one month (Fig. 5). Identifying mismatches with the initially chosen workstations triggered switching to other workstations: 'First, I sat closer to the entrance. Later I moved away because of too much traffic' (P2-S1). One of the experimenters mentioned a need for having visual representations for facilitating work as a motive for dwelling:

Figure 5: An experimenter's choices of workstations during the fieldwork.

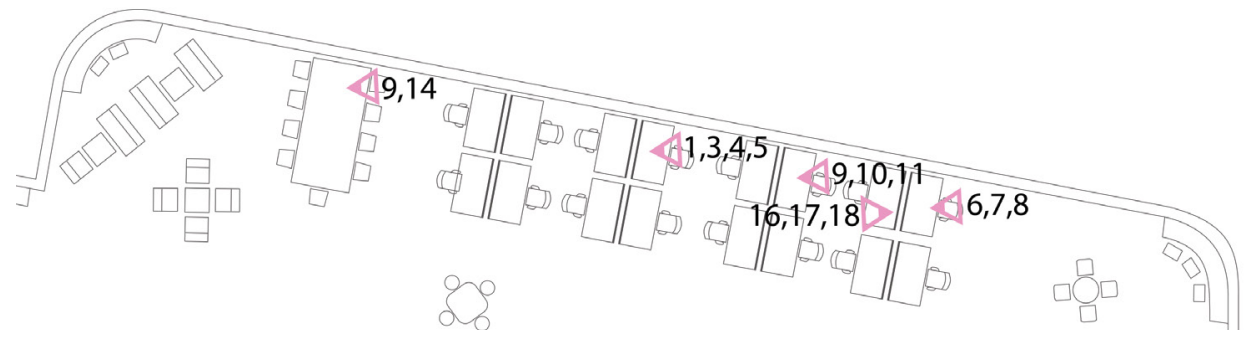


'I draw when I want to understand a context or when I want to figure out how to raise interest among a group. I figured I want to have this moodboard somewhere; otherwise it will hinder my ability to fulfil my work tasks. So I went to a desk and started pinning up things. It was liberating' (P3-S4).

During the exploratory phase, the experimenters started following the desk-sharing policy (Fig. 6): 'I have started moving around as intended. I removed my stuff and put them all in the lockers' (P3-S7). This phase involved adapting oneself to the spatial configuration: 'I have to become better at sifting out distractions' (P9-S1) and finding routines that facilitated switching workstations and minimized setup time: 'I skip the mouse and keyboard now and only work on my laptop' (P3-S8). These explorations led to identifying benefits of the different workstations: 'it is nice to sit there; everyone can see where I am. I am available for others but no one sits behind me (P7-S6)'. When following the desk-sharing policy, the experimenters appreciated switching workstations: 'I get inspired by trying different things and environments' (P3-S7).

Figure 6: Shifting between rejecting (Right: claiming and personalising a workspace, Session 4) and adopting the desk-sharing policy (Left: removing belongings from the desks and storing them in assigned shelves, Session 7).
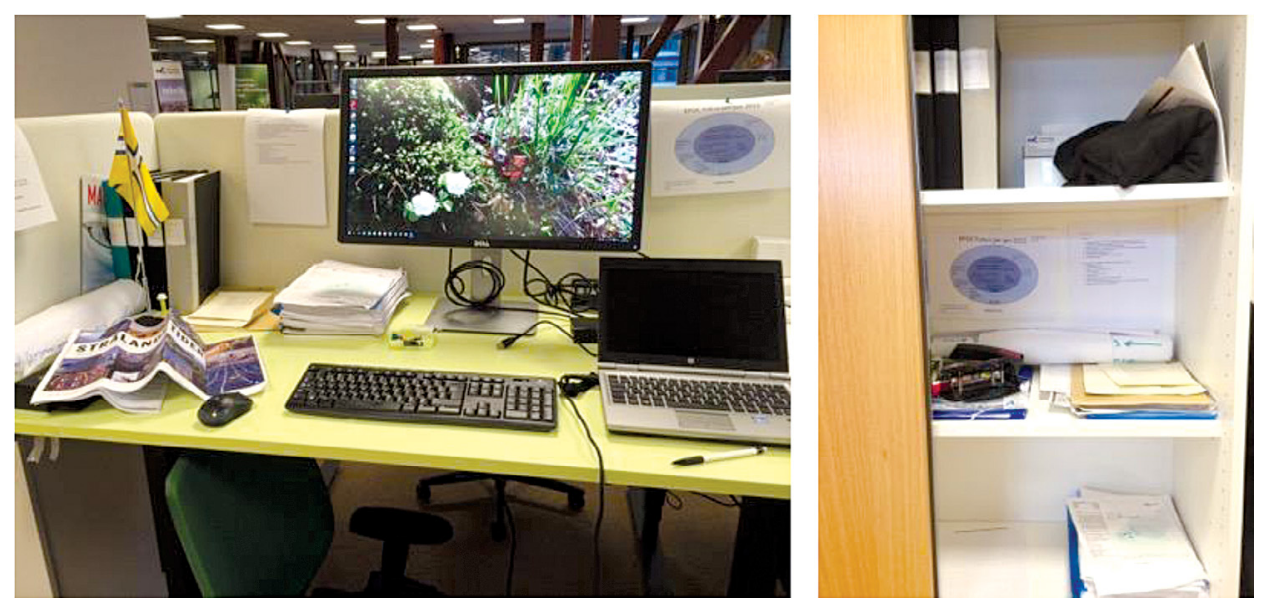

\section{Summary: Appropriation and nonappropriation of the desk-sharing policy}

The processes of appropriating the desk-sharing policy among mobile workers, dwellers, and experimenters are summarized in Fig. 7. For mobile workers and experimenters, appropriating the desk-sharing policy involved identifying a few preferred workstations and finding compromises to minimise setup time. They chose workstations close to their immediate colleagues. Their choices excluded back-up rooms or workspaces that isolated them from their colleagues or required them to sit together 
with other tenants (especially the spaces on the other side of the bridge). After having identified preferred workstations, they repeatedly returned to the same workstation, but removed their belongings when they were elsewhere. In contrast, dwellers used the same workstation and left their belongings at that workstation throughout the fieldwork. This was to minimize the misfits of the A-FO solution that they would otherwise encounter.

Figure 7: Phases of appropriation of desk-sharing policy for different use profiles.

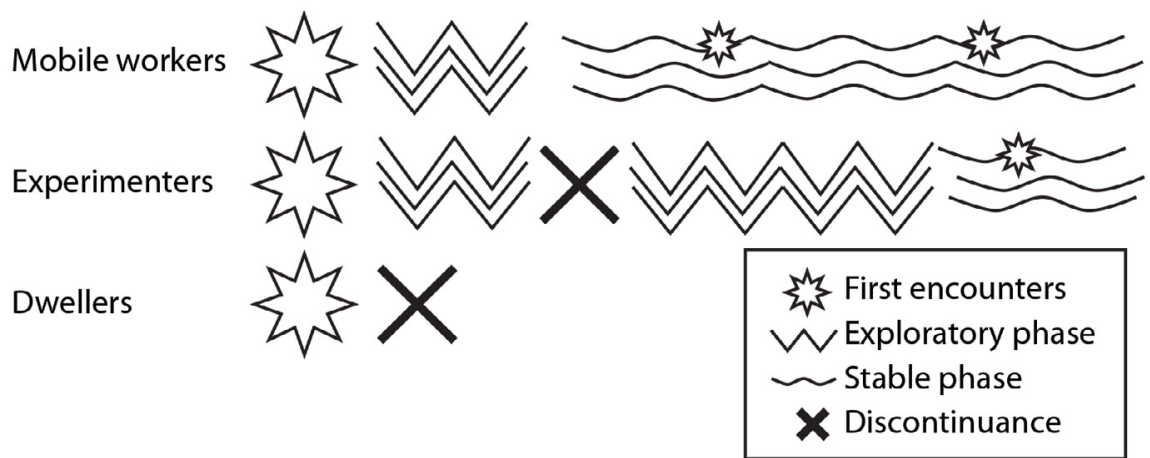

The participants created a 'wish-list' for the facility management to communicate issues that hindered mobility, such as incompatibility of the screens with the participants' laptops, insufficient personal storage, the placement of power outlets on the desks that were difficult to reach, and problems with booking workstations and Internet and phone coverage in back-up rooms. The list was created at the first shadowing session and updated throughout the fieldwork. The facility management and IT support addressed most of these issues. However, setup time was not eliminated when switching workstations. Switching workstations in the stable phases involved being introduced to a new setting, in addition to a need for setting up and packing away belongings.

\section{Modes of interaction arising from the spatial configuration and emergent speech policies}

The process of appropriating the A-FO solution with respect to the spatial configuration and speech policies was divided into three phases: an initial no-policy period, emergence of a speech policy, and discontinuation of the speech policy. After a period of familiarization with the new premises, some of the participants proposed a quiet speech policy for the open workspaces. The policy was tested during sessions 5 to 9 , but was later discontinued. The extent of participants' interactions changed due to the reinvention of the concept, that is, defining, testing, and modifying speech policies. The different modes and locations of interactions in each phase are summarized in Table 3. 
Table 3 Temporal changes in modes of interaction arising from the spatial configuration and emergent speech policies. Observed changes in the extent of interactions over time are marked with $\uparrow$ (increased) and $\downarrow$ (decreased).

\begin{tabular}{|c|c|c|c|}
\hline $\begin{array}{l}\text { Modes of } \\
\text { interaction }\end{array}$ & $\begin{array}{l}\text { Initial no-policy phase } \\
\text { (SI-4) }\end{array}$ & $\begin{array}{l}\text { Emergence of an } \\
\text { explicit quiet speech } \\
\text { policy (S5-9) }\end{array}$ & $\begin{array}{l}\text { Emergence of an } \\
\text { implicit semi-quiet } \\
\text { speech policy (SI0-18) }\end{array}$ \\
\hline $\begin{array}{l}\text { Spontaneous } \\
\text { interactions }\end{array}$ & $\begin{array}{l}\text { - at desks } \\
\text { - across desks } \\
\text { - in multiple locations } \\
\text { - corridor meetings }\end{array}$ & $\begin{array}{l}\text { - at desks } \uparrow \\
\text { - across desks } \downarrow \\
\text { - in multiple locations } \uparrow \\
\text { - corridor meetings } \downarrow \\
\text { - indirect interactions } \uparrow\end{array}$ & $\begin{array}{l}\text { - at desks } \\
\text { - across desks } \\
\text { - in multiple locations } \downarrow \\
\text { - corridor meetings } \uparrow\end{array}$ \\
\hline Phone calls & $\begin{array}{l}\text { - at desks } \\
\text { - in multiple locations } \\
\text { - in back-up rooms }\end{array}$ & $\begin{array}{l}\text { - at desks } \\
\text { - in multiple locations } \uparrow \\
\text { - in back-up rooms } \uparrow\end{array}$ & $\begin{array}{l}\text { - at desks } \uparrow \\
\text { - in multiple locations } \\
\text { - in back-up rooms }\end{array}$ \\
\hline Open meetings & - meeting/project furniture & - meeting/project furniture & - meeting/project furniture $\uparrow$ \\
\hline $\begin{array}{l}\text { Pre-/post-meeting } \\
\text { interactions }\end{array}$ & $\begin{array}{l}\text { - at entrance } \\
\text { - in multiple locations }\end{array}$ & $\begin{array}{l}\text { - at entrance } \\
\text { - in multiple locations }\end{array}$ & $\begin{array}{l}\text { - at entrance } \\
\text { - in multiple locations }\end{array}$ \\
\hline $\begin{array}{l}\text { Being dragged to/ } \\
\text { joining }\end{array}$ & $\begin{array}{l}\text { - qs to all } \\
\text { - being approached }\end{array}$ & $\begin{array}{l}\text { - qs to all } \downarrow \\
\text { - being approached }\end{array}$ & $\begin{array}{l}\text { - qs to all } \downarrow \\
\text { - being approached }\end{array}$ \\
\hline
\end{tabular}

\section{First encounters: Initial no-policy period (sessions I-4)}

The open spaces had no explicit speech policy. During the first four sessions, the premises were either (i) quiet, that is, the participants were either quiet or whispered when talking to each other and fewer interactions were observed (Fig. 8a), or (ii) lively, that is, the participants talked loudly and more interactions were observed (Fig. 8b). This phase was mostly explorative and involved trial and error. The recurrent modes of interaction observed in the no-policy period were

- Short spontaneous interactions that involved exchanging information for (i) locating colleagues: 'I am going to sit here today', or (ii) giving updates regarding ongoing work. These interactions took place in the open spaces, enabling others to access the information that was being shared.

- Multi-locational phone calls initiated at the computer desks and continued in open spaces adjacent to other desks, or on the way out: 'our new challenge is to find a corner where we don't distract each other' (P8-S2). Some of these calls involved going back to the desks to fetch laptops or documents.

- Pre-/post-meeting interactions involved conversations either on the way to the meeting room or at the entrance in proximity to the open zone. The furniture placed at the entrance created a waiting hub for the meeting attendees.

- Joining/being dragged into conversations involved (i) overhearing and joining conversations, (ii) questions that addressed everyone, or (iii) being approached by coworkers, visitors, or other tenants.

- Planned or unplanned open meetings that involved 'side-by-side' or 'face-to-face' collaborations with immediate colleagues or external collaborators. 
Figure 8: Mapping of observed interactions among the participants in sessions 2 and 3: unmarked triangles (spontaneous interactions), OM (open meetings), PM (pre-/post-meeting interactions), J (joining/being dragged to), arrows (multi-locational interactions). Different colors represent the participants, while the grey triangles represent other tenants or visitors.
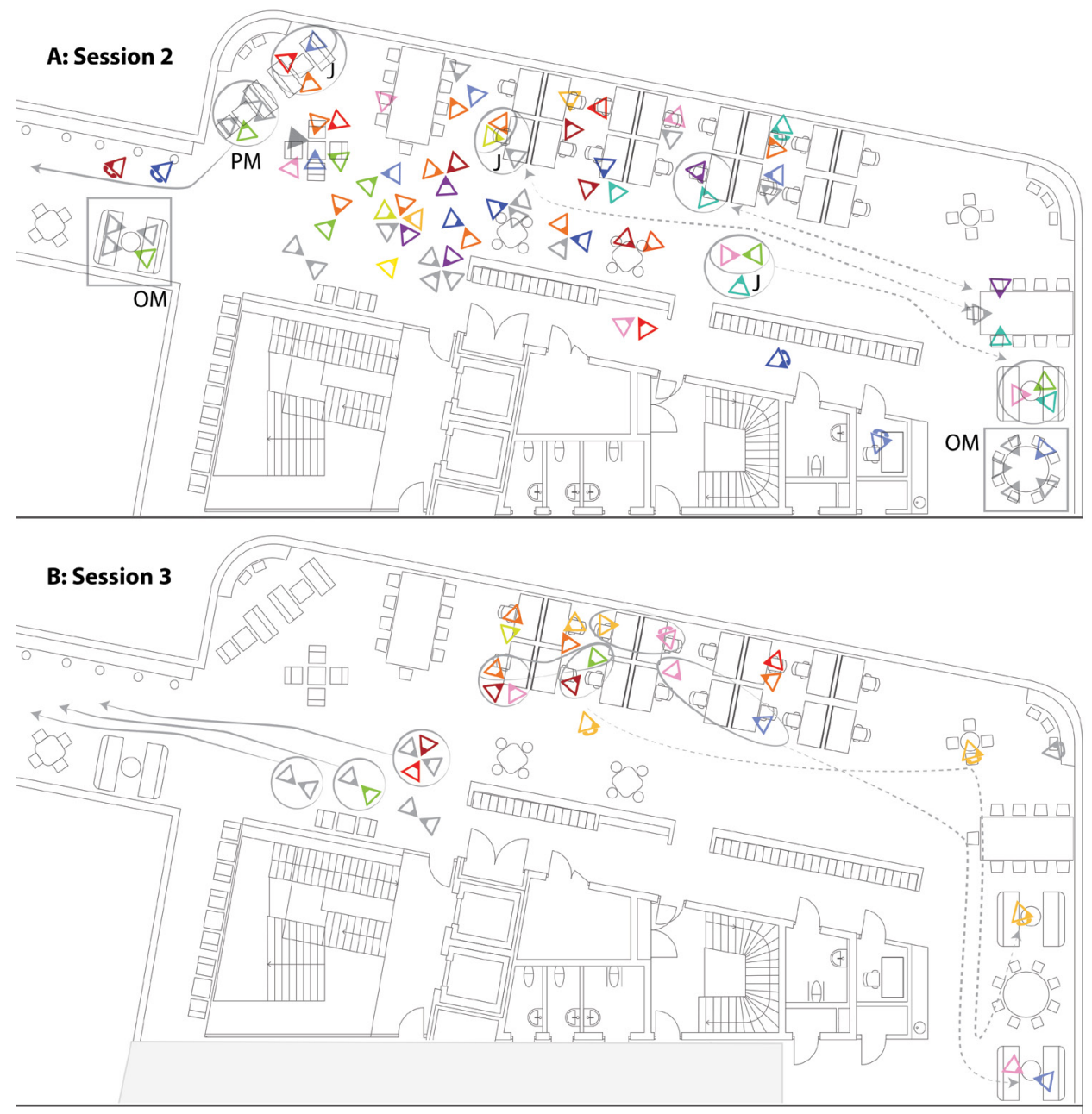

The above modes of interactions were observed more frequently during the loud days. This led to distractions and discomfort for the participants: 'if I really want to get something done, I can't do it here. If I don't greet others, I feel like an unwelcoming person. It is really annoying' (P7-S4). This was due to (i) the placement of the furniture for collaborative work that was mostly located in proximity to the workspaces intended for solitary work, (ii) placement of a waiting lounge at the entrance, and (iii) lack of speech policies in the open workspaces. The lack of explicit speech policy was considered confusing and frustrating for most of the participants: 'I don't really get this. Should it be a quiet environment where you move away if you want to talk? Or should it be lively? I 
think the worst situation is now when it is not clear what policies apply' (P3-S3). Some of the participants who needed a space to concentrate chose the backup rooms. However, working in the backup rooms entailed making oneself unavailable for others. This led to frustrations for the participants who wanted to allow others the opportunity for interaction and simultaneously wished to carry out prolonged uninterrupted solitary work, for instance writing a report.

\section{Exploration:Emergenceandappropriation of aquietspeechpolicy(sessions 5-9)}

Due to a need for uninterrupted work, some of the participants proposed having a quiet speech policy. This was not welcomed by the participants whose work involved more collaboration: 'I could accept having a quiet environment. But this implies that I will be here as little as possible' (P3-S4). Nonetheless, the participants collectively agreed on implementing a quiet speech policy in the open workspaces. The premises were generally quiet during observation sessions 5-9, which resembled the quiet episodes in the nopolicy period (Fig. 8b): 'it's been like a library for the past two days. Everyone whispers. We have to show more respect' (P6-S5). As a result of adopting the quiet speech policy, the nature of interactions changed and new routines emerged:

- Short spontaneous interactions: (i) the participants approached each other at their desks and whispered when exchanging information, (ii) questions that addressed everyone were eliminated to a large extent, (iii) fewer instances of 'corridor meetings' were observed.

- Occurrences of multi-locational meetings and phone calls increased.

- Indirect interactions mediated through project boards: The boards were created in Session 4 to (i) document and communicate the status of ongoing projects instead of informal information exchanges, and (ii) cope with unavailability of the spatially dispersed colleagues who followed the desk-sharing policy: 'It is more difficult to get an overview of what we do here. Everyone moves around. It was probably like this before. But you see it in a different way here.' (P9-S4). The participants updated the information and read others' updates on the board, minimizing the need for informal status updates.

- Weekly meetings were moved from Tuesdays to Mondays to accommodate the majority of the participants. This was suggested at Session 8 where the participants expressed concerns about losing overview of the ongoing activities due to (i) spatially dispersed colleagues, and (ii) implementation of the quiet speech policy that had led to limited access to the information that was otherwise spontaneously exchanged.

The above changes involved learning when and how to interact with each other in order to maintain quiet workspaces. However, some modes of interaction were observed that hindered maintaining a quiet workspace. Firstly, the open meetings were not eliminated during this period, since the furniture for collaborative work was in proximity to the spaces that were desired to be quiet. Secondly, post-/pre-meeting interactions at the entrance continued to cause distractions for the participants: 'it is annoying that people continue talking when they enter' (P12-S18). The workspaces for solitary work were in 
proximity to the entrance and the furniture that invited visitors to wait. Lastly, some participants occasionally held phone calls at desks: 'it is difficult to move your stuff for a phone call' (P4-S5). To maintain a quiet workspace, it was necessary to (i) modify the configuration of the premises, for example, by separating the workspaces for solitary and collaborative work and the waiting lounge, (ii) clearly communicate and mark the spaces that were to be quiet to inform and remind other tenants and guests, especially as new tenants joined, and (iii) follow the desk-sharing and the speech policy, and make appropriate workstation choices, for instance switching to lively workspaces or backup rooms when expecting phone calls.

\section{Discontinuance of the quiet speech policy (session I0-18)}

During sessions 10-18, the open workspaces were semi-quiet, that is, they shifted between being quiet and lively: instances where the participants either did not interact with each other or whispered when interacting, followed by outbursts of loud interactions. There was however no explicit communication of the discontinuation of the quiet speech policy. The observed changes in modes of interaction were

- 'Corridor meetings' adjacent to the workstations occurred more frequently.

- 'Multi-locational meetings' were eliminated, since the participants learned that the semi-enclosed furniture did not isolate their conversations.

- More instances of open meetings were observed. In addition, pre-/post-meeting interactions continued to take place.

- The number of phone calls at desks increased.

Discontinuation of the quiet speech policy was a result of (i) the spatial obstacles to maintaining quiet workspaces, (ii) a lack of interest in having quiet spaces among some of the participants as their work involved more collaboration, (iii) ambiguity and a lack of communication of the policy, and (iv) inappropriate workstation choices, that is, choosing lively spaces for concentrative work and vice versa.

\section{Summary: emergence, appropriation, and discontinuation of a speech policy}

After recognizing a lack of quiet workspaces, the participants engaged in the exploration of different solutions. As a result, the premises were either quiet or lively during the initial no-policy period. The participants agreed on implementing a quiet speech policy between sessions 4 and 5 . This led to changes in routines and modes of interaction that minimized distractions in open spaces. However, several issues hindered maintaining quiet workspaces, such as insufficient distance and separating panels. The participants put together a 'wish-list' to communicate the issues with the facility management. However, these shortcomings were not resolved, leading to discontinuation of the quiet speech policy and having an implicit semi-quiet speech policy (Fig. 9). 
Figure 9: Different phases of appropriating emergent speech policies.

$$
\begin{aligned}
& \text { Initial no-policy } \\
& \text { period (S1-4) }
\end{aligned}
$$
Emergence, appropriation, and discontinuance of a quiet speech policy (S5-9)

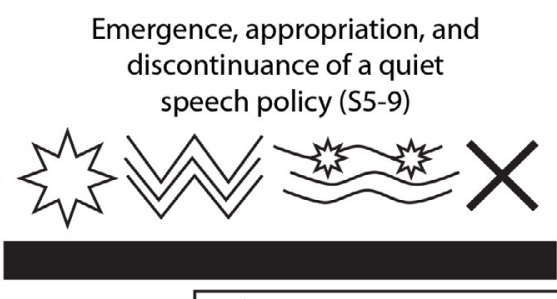

First encounters
Emergence of an implicit semi-quiet speech policy (S10-18)

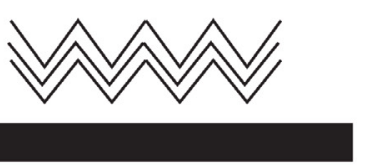

〜 Stable phase

X Discontinuance

\section{Discussions and implications}

The purpose of this study was to explore how employees appropriate the different aspects of an A-FO into their daily work. The following discussion summarizes the insights from the study, addresses the reasons behind appropriation, nonappropriation and discontinuation of desk-sharing and speech policies. While the primary aim of this paper was to understand the appropriation process, the identified reasons behind adoption and rejection of the desk-sharing and speech policies are used to suggest guidelines for addressing benefits and pitfalls when implementing A-FOs.

Relocating to the A-FO involved infusing a large number of new artefacts and introducing new work practices, that is, the desk-sharing policy. The employees had to find ways to incorporate these artefacts and policies into their daily work. Different phases of appropriating desk-sharing policy were first encounters, exploration, and a stable phase that involved discontinuation and/or redefinition of the policies. The duration of these phases varied: (i) the mobile workers had a short period of exploration, (ii) the experimenters had a longer exploration phase, and (iii) the dwellers did not experiment with switching workstations. The process of appropriating the A-FO with respect to speech policies involved an initial no-policy period, emergence, and appropriation of a quiet speech policy, and discontinuance of the policy.

\section{Why do some users appropriate the desk-sharing policy while others do not?}

While half the participants appropriated the desk-sharing concept (mobile workers and experimenters), others (dwellers) used one workstation and left their belongings on that workstation throughout the fieldwork. Other studies of A-FO also report a low rate of switching behavior among employees (Appel-Meulenbroek et al., 2011; Hoendervanger et al., 2016; Tagliaro \& Ciaramella , 2016). The relatively low rate of adoption of the desk-sharing policy may partly be due to insufficient involvement of the participants in the design and planning process and limited opportunities to influence and improve their work environment after relocation. This was due to facility management's desire to keep the premises as generic as possible for accommodating different organizations and tenants. According to van Koetsveld and Kamperman (2011), user involvement is critical for successful implementation of A-FOs. Apart 
from user involvement, it is important to discuss the A-FO solution with respect to attributes of innovation (cf. Rogers, 1995) and whether it matched employees' needs.

\section{Relative advantage}

The participants who appropriated the desk-sharing concept found benefits with the ease of access to information and coworkers. On the other hand, dwellers did not find the concept a better alternative than having assigned workstations, as it introduced misfits in their daily work. Perceiving relative advantages and usefulness in innovations is significant for accepting and adopting innovations (Davis, 1989; Rogers, 1995). One of the main disadvantages of the desk-sharing policy was increased effort and loss of time when setting up workstations workstations, that is, fetching artefacts from the lockers and overcoming the technical problems. Other studies of A-FOs show that loss of time when switching workstations has a negative impact on individuals' productivity (e.g., Kim et al., 2016). Furthermore, studies of the appropriation of technology highlight that setup time discourages users from appropriating a technology (Bowers, 1994). Another disadvantage of the A-FO solution was the insufficient number of quiet workspaces that introduced misfits with the participants' concentrative work activities. In other words, switching workstations for the dwellers would not provide them with a more fitting workstation. The ability to choose a quiet workspace is regarded as one of the main benefits of A-FOs (Wohlers \& Hertel, 2016). Better zoning in this case (sufficient enclosed and/or open quiet workspaces with quiet speech policies) may have encouraged the dwellers to follow the desk-sharing policy.

\section{Compatibility}

Appropriating the desk-sharing policy among the mobile workers did not require substantial changes in their ways of working (switching workstations was compatible with their work), while it involved finding new routines and ways of working for the experimenters. According to Rossitto et al. (2014), some users can be more familiar than others with the use of a particular technology or a concept. For the mobile workers, the A-FO involved fewer items to appropriate, since they had a more or less flexible way of working prior to relocation, for example, they were used to working without a mouse and a keyboard. On the other hand, other participants who used such instruments had to set up more items when switching workstations. Adopting a flexible way of working was incompatible with the dwellers' needs and past experiences. It is also important to highlight that there are different types of knowledge work in coworking spaces depending on the level of mobility and interactions (Greene \& Myerson, 2011). In other words, dwelling was a reasonable way of appropriating the A-FO solution, as their activities involved less collaboration than their peers.

\section{Complexity}

The multitude of new concepts and artefacts infused into the participants' artefact ecologies and the complexity it introduced may explain why some of the participants 
did not appropriate the whole system. Rejecting the desk-sharing policy involved a rejection of the majority of workstations, i.e. the dwellers appropriated some parts of the A-FO, while the experimenters and the mobile workers appropriated the A-FO as a whole (i.e., adopted the desk-sharing policy and used different workstations). Another complexity introduced by the desk-sharing policy was to become less reliant on printed documents. Studies of the use of paper in offices highlight that office workers will continue relying on paper for knowledge work (such as writing, reviewing, planning and thinking, and collaborating and communicating) despite the increased use of digital alternatives (Sellen \& Harper, 2003). Learning to become mobile workers required effort and time to plan and restructure work. Perceiving an innovation as difficult and complex to use leads to its rejection among users (Davis, 1989; Rogers, 1995). Other complexities identified in the literature on A-FOs concern difficulties to find colleagues and colocate (Ekstrand \& Karsten Hansen, 2016). However, due to the high ratio of workstations per employee and the employees' workstation choices in proximity to each other, these complexities neither were observed nor mentioned by the participants.

\section{Observability}

While those who appropriated a desk-sharing policy saw benefits with the A-FO, the effects and expected positive outcomes of having an A-FO were not clear for the dwellers due to lack of quiet spaces and lack of a need for rotation. This can also explain why the mobile workers and experimenters limited their choices of workstations to a few desks in proximity to the dwellers: they did not find benefits with workstations in the other zones. It is also important to highlight that no problems with capacity were observed or reported during the fieldwork. As a result, rejecting the desk-sharing policy and leaving one's belongings did not lead to shortage of workstations for colleagues or the other tenants. In A-FOs with a lower capacity, employees may recognize the importance of freeing up workstations and therefore follow the desk-sharing policy.

\section{Trialability}

The results showed that the experimenters' long process of exploration led to finding new ways of working in the A-FO, while the dwellers used one workstation throughout the fieldwork. The process of appropriating is described as the 'interplay between the situation at hand and in negotiation between proposers and adopters' (Rossitto et al., 2014). This negotiation was observed among the participants not only for appropriating desk-sharing policy but also for introducing and implementing a quiet speech policy. However, trying a speech policy per se did not provide quiet spaces for uninterrupted work. The participants' efforts at implementing and maintaining a quiet speech policy were not successful due to (i) the spatial configuration, (ii) nonappropriation of the speech policy and desk-sharing by some of the participants, and (iii) failure in communicating the quiet speech policy with other tenants or visitors. 


\section{Impliciations for organizations implementing A-FOs}

The adoption and appropriation of the desk-sharing policy is a choice made by the employee, after a prior decision to implement the policy by the organization and/or the facility management (cf. contingent decision in Rogers, 1995, p. 372). In studies on appropriation of technology, users make an active choice in acquiring and discarding artefacts (e.g., Bødker \& Klokmose, 2012; Jung et al., 2008). In an organizational context, the employees may have limited freedom in acquiring and/or discarding technological resources, as it was in this case. In addition, it is not one artefact or software application that is being acquired and adopted when relocating to an A-FO, but a large number of new artefacts as well as new work practices. It is therefore important to consider different ways of appropriating the A-FO concept: adopting, experimenting with, rejecting the desk-sharing policy, as well as different modes of interaction arising from the spatial configuration and speech policies.

In the context of Nordic working life, researchers emphasize the voice of employees who are members of collectives sharing their ideas and aspirations and influencing the management (Hasle \& Sørensen, 2013). Work environment authorities stress the importance of employee participation and involvement in systematic work environment management (Swedish Work Environment Authority, 2001). Involving employees, especially in early phases of planning A-FOs, can lead to a collective sense of ownership and therefore may minimize rejection of the new system. This involvement can also reduce the potential risk of feeling excluded since the rejection of desksharing policy may create a sense of exclusion or isolation from the rest of the organization that follows the policy. Further, work environment improvements can be achieved by addressing the issues that the employees may raise both before and after relocation. It is therefore important to introduce some flexibility into the solution, that is to say allowing for modification and tailoring to meet employees' needs. To ensure a good work environment for as many individuals as possible in A-FOs, it is important to minimize obstacles that may be introduced for employees in their work, and allow for prolonged uninterrupted work. This requires thought-through spatial configuration and clear speech policies, as well as negligible setup time when switching workstations.

The results showed that the participants' initial period of getting familiarized with the new premises involved identifying fits and misfits of the different workstations. This period of excitement, according to Bødker and Klokmose (2012), is associated with the initial phases of using an artefact and may also be experienced in later phases as one's needs and expectations change over time. Following desk-sharing policy involves changing some artefacts on a daily basis (when switching workstations) during the stable state of appropriation. This change in ways of working demands a set-up time that was minimized for the mobile workers and the experimenters due to the strategies and routines they found to be viable (e.g., discontinuing the use of mouse, keyboards, large screens, and limiting their location to several workstations that required less preparation). However, the setup time was not eliminated and led to fragmentation of work and brief periods of excitement in the otherwise stable state of appropriation. It is therefore of great importance to address the setup issues and the negative excitement they may entail. On the other hand, the participants also experienced positive excitement as a 
result of switching workstations in the stable phase, for example, getting inspired by changing the environment.

To facilitate appropriation of the desk-sharing policy, switching workstations should involve relative and observable advantages over having assigned desks. Furthermore, the desk-sharing policy should be compatible with individuals' work needs and the artefacts brought into the A-FO and introduce minimal complexities in daily work. One way to make the relative advantages of desk-sharing policy observable for employees may be to engage in collective exploration of the workspaces after relocation. Creating situations where employees collectively explore the concept may reveal the otherwise hidden advantages of switching workstations.

\section{Methodological considerations}

Carrying out a shadowing study over six months made it possible to capture the process of appropriating the A-FO concept and the temporal aspects of learning to use the A-FO. The participants who were shadowed in this study worked for one of the organizations in the coworking spaces. The results from this study were in line with studies on A-FOs, for example, the participants chose workstations in close proximity to their immediate colleagues or team members (cf. Appel-Meulenbroek et al., 2011; Qu et al., 2010). The findings that may be particular to this case study are the rate of adoption with respect to desk-sharing policy and emergence of speech policies. The more generalizable findings are (i) different ways of appropriating A-FOs, (ii) the stages of appropriation, and (iii) the outlined reasons behind rejection of desk-sharing policies.

\section{Concluding remarks}

This shadowing study showed how employees appropriate a multitude of new artefacts and policies and incorporate them into their work context when relocating to an A-FO. Different ways of appropriating A-FOs were identified: (i) adopting, experimenting with, or rejecting the desk-sharing policy, and (ii) modes of interaction arising from spatial configuration and emergent speech policies. Furthermore, phases of appropriation were described: first encounters, exploration, and stable phases, as well as discontinuation and redefinition of the policies.

In addition to the employees' limited involvement in the design and planning process, the underlying reasons behind nonappropriation of the desk-sharing policy were (i) relative disadvantages such as misfits with work needs and increased time and effort, (ii) incompatibility with previous ways of working or with individuals' brought-in artefacts such as laptops, (iii) increased complexity such as limitations on use of paper documents, (iv) un-observability of benefits due to poorly designed layout, lack of quiet spaces, and lack of a need to free up space for others, and (v) problems with trialability due to set-up complications.

The insights from this study can provide support for organizations, designers, and change process managers when considering A-FOs, specifically to develop strategies for supporting uninterrupted work and minimizing misfits when relocating to A-FOs. 


\section{References}

Allvin, M., Mellner, C., Movitz, F. and Aronsson, G. (2013). The diffusion of flexibility: estimating the incidence of low-regulated working conditions. Nordic journal of working life studies, 3, 99. doi: http://dx.doi.org/10.19154/njwls.v3i3.3013.

Appel-Meulenbroek, R., Groenen, P. and Janssen, I. 2011. An end-user's perspective on activity-based office concepts. Journal of Corporate Real Estate, 13, 122-135. doi: http://dx.doi.org/10.1108/14630011111136830.

Bodin Danielsson, C. and Bodin, L. (2008). Office type in relation to health, well-being, and job satisfaction among employees. Environment and Behavior, 40, 636-668. doi: http:// dx.doi.org/10.1177/0013916507307459.

Bødker, S. and Klokmose, C. N. (2011). The Human-Artifact Model: An Activity Theoretical Approach to Artifact Ecologies. Human-Computer Interaction, 26, 315-371. doi: http://dx.doi.org/10.1080/07370024.2011.626709.

Bødker, S. and Klokmose, C. N. (2012). Dynamics in artifact ecologies. Proceedings of the 7th Nordic Conference on Human-Computer Interaction: Making Sense Through Design, 2012. ACM, 448-457.

Boutellier, R., Ullman, F., Schreiber, J. and Naef, R. (2008). Impact of office layout on communication in a science-driven business. R\&D Management, 38, 372-391. doi: http://dx.doi.org/10.1111/j.1467-9310.2008.00524.x.

Bowers, J. (1994). The work to make a network work: studying CSCW in action. Proceedings of the 1994 ACM conference on Computer supported cooperative work, 1994. ACM, 287-298.

Brunia, S., De Been, I., and van der Voordt, T. J. (2016). Accommodating new ways of working: lessons from best practices and worst cases. Journal of Corporate Real Estate 18: 30-47. doi: https://doi.org/10.1108/JCRE-10-2015-0028.

Carroll, J., Howard, S., Vetere, F., Peck, J. and Murphy, J. (2002). Just what do the youth of today want? Technology appropriation by young people. System Sciences, 2002. HICSS. Proceedings of the 35th Annual Hawaii International Conference on, 2002. IEEE, 1777-1785.

Creswell, J. W. (2013). Research Design: Qualitative, Quantitative, and Mixed Methods Approaches, SAGE Publications.

Czarniawska, B. (2007). Shadowing: And Other Techniques for Doing Fieldwork in Modern Societies, Liber.

Davis, F. D. (1989). Perceived usefulness, perceived ease of use, and user acceptance of information technology. MIS quarterly, 319-340.

De Been, I. and Beijer, M. (2014). The influence of office type on satisfaction and perceived productivity support. Journal of Facilities Management, 12, 142-157. doi: http://dx.doi.org/10.1108/JFM-02-2013-0011.

Ekstrand, M., and Karsten Hansen, G. (2016). Make it work! Creating an integrated workplace concept. Journal of Corporate Real Estate, 18, 17-29. doi: https://doi.org/10.1108/ LCRE-10-2015-0031.

Frick, K. (2013). Work environment dialogue in a Swedish municipality-strengths and limits of the Nordic work environment model. Nordic journal of working life studies, 3, 69. doi: http://dx.doi.org/10.19154/njwls.v3i1.2521.

Greene, C. and Myerson, J. (2011). Space for thought: designing for knowledge workers. Facilities, 29, 19-30. doi: https://doi.org/10.1108/02632771111101304.

Hasle, P. and Sørensen, O. H. (2013). Employees as Individually and Collectively Acting Subjects-Key Contributions from Nordic Working Life Research. Nordic Journal of Working Life Studies, 3, 9. doi: http://dx.doi.org/10.19154/njwls.v3i3.3009. 
Hirst, A. (2011). Settlers, vagrants and mutual indifference: unintended consequences of hot-desking. Journal of Organizational Change Management, 24, 767-788. doi: http://dx.doi.org/10.1108/09534811111175742.

Hoendervanger, J. G., De Been, I., van Yperen, N. W., Mobach, M. P. and Albers, C. J. (2016). Flexibility in use: Switching behaviour and satisfaction in activity-based work environments. Journal of Corporate Real Estate, 18, 48-62. doi: http://dx.doi.org/10.1108/ LCRE-10-2015-0033.

Jung, H., Stolterman, E., Ryan, W., Thompson, T. and Siegel, M. (2008). Toward a framework for ecologies of artifacts: how are digital artifacts interconnected within a personal life? Proceedings of the 5th Nordic conference on Human-computer interaction: building bridges, 2008. ACM, 201-210.

Kim, J., Candido, C., Thomas, L. and De Dear, R. (2016). Desk ownership in the workplace: The effect of non-territorial working on employee workplace satisfaction, perceived productivity and health. Building and Environment, 103, 203-214. doi: http://dx.doi. org/10.1016/j.buildenv.2016.04.015.

Knight, C. and Haslam, S. A. (2010). The relative merits of lean, enriched, and empowered offices: an experimental examination of the impact of workspace management strategies on well-being and productivity. Journal of Experimental Psychology: Applied, 16, 158. doi: http://dx.doi.org/10.1037/a0019292.

Kojo, I. and Nenonen, S. (2016). Typologies for co-working spaces in Finland-what and how? Facilities, 34, 302-313. doi: https://doi.org/10.1108/F-08-2014-0066.

Meijer, E. M., Frings-Dresen, M. H. and Sluiter, J. K. (2009). Effects of office innovation on office workers' health and performance. Ergonomics, 52, 1027-1038. doi:

Merriam, S. B. (2009). Qualitative Research : A Guide to Design and Implementation (3), Somerset, US, Jossey-Bass.

Miles, M. B. and Huberman, A. M. (1994). Qualitative Data Analysis: An Expanded Sourcebook, SAGE Publications.

Myerson, J. and Ross, P. (2003). The 21st Century Office, Laurence King Publishing.

Parrino, L. (2015). Coworking: assessing the role of proximity in knowledge exchange. Knowledge Management Research and Practice, 13, 261-271. doi: https://doi.org/10.1057/ kmrp.2013.47.

Qu, X., Zhang, X., Izato, T., Munemoto, J. and Matsushita, D. (2010). Behavior concerning choosing workstations in non-territorial offices. Journal of Asian Architecture and Building Engineering, 9, 95-102. doi: https://doi.org/10.3130/jaabe.9.95.

Rogers, E. M. (1995). Diffusion of Innovations, 4th Edition, Free Press.

Ross, P. K., Ressia, S., Sander, E. J. and Parry, E. (2017). Work in the 21st Century: How Do I Log On?, Emerald Publishing Limited.

Rossitto, C., Bogdan, C. and Severinson-Eklundh, K. (2014). Understanding Constellations of Technologies in Use in a Collaborative Nomadic Setting. Computer Supported Cooperative Work (CSCW), 23, 137-161. doi: http://dx.doi.org/10.1007/s10606-013-9196-4.

Seddigh, A., Berntson, E., Danielson, C., and Westerlund, H. (2014). Concentration requirements modify the effect of office type on indicators of health and performance. Journal of Environmental Psychology, 38: 167-174. doi: http://dx.doi.org/10.1016/j.jenvp. 2014.01.009.

Sellen, A. J. and Harper, R. H. R. (2003). The Myth of the Paperless Office, MIT Press.

Sim, E. and Heywood, C. (2017). Towards a holistic assessment of employees' acceptance of innovative workplace designs. European Real Estate Society (ERES) Conference.

Skogland, M. A. C. (2017). A spatial approach to transformational change: Strategic alignment of the spatial and cultural environment. Journal of Corporate Real Estate, 00-00. doi: https://doi.org/10.1108/JCRE-09-2016-0030. 
Spinuzzi, C. (2012). Working alone together: Coworking as emergent collaborative activity. Journal of Business and Technical Communication, 26, 399-441. doi: https://doi. org/10.1177/1050651912444070.

Sundstrom, E. and Sundstrom, M. G. (1986). Work Places: The Psychology of the Physical Environment in Offices and Factories, Cambridge University Press.

Swedish Work Environment Authority (2001). Systematic Work Environment Management. Swedish Work Environment Authority Provisions 2001:1. Solna.

Swedish Work Environment Authority (2016). The Work Environment 2015. Arbetsmiljöstatistik Rapport 2016:2. ISSN 1652-1110.

Tagliaro, C. and Ciaramella, A. (2016). Experiencing smart working: a case study on workplace change management in Italy. Journal of Corporate Real Estate, 18, 194-208. doi: https://doi.org/10.1108/JCRE-10-2015-0034.

Van Der Voordt, T. J. (2004). Productivity and employee satisfaction in flexible workplaces. Journal of Corporate Real Estate, 6, 133-148. doi: http://dx.doi.org/10.1108/ 14630010410812306.

Van Koetsveld, R., and Kamperman, L. (2011). How flexible workplace strategies can be made successful at the operational level. Corporate Real Estate Journal, 1(4), 303-319.

Van Meel, J. (2000). The European Office: Office Design and National Context, 010 Publishers.

Vos, P. and van Der Voordt, T. (2002). Tomorrow's offices through today's eyes: effects of innovation in the working environment. Journal of Corporate Real Estate, 4, 48-65. doi: http://dx.doi.org/10.1108/14630010210811778.

Wohlers, C. and Hertel, G. (2016). Choosing where to work at work - towards a theoretical model of benefits and risks of activity-based flexible offices. Ergonomics, 1-20. doi: http://dx.doi.org/10.1080/00140139.2016.1188220. 